\title{
A comparative study of early postoperative feeding versus conventional feeding for patients undergoing caesarean section
}

\author{
S. Neeraja*, Naritha Reddy, Naima Fathima
}

Department of Obstetrics and Gynecology, SVS Medical College, Mahabubnagar, Telangana, India

Received: 11 October 2019

Accepted: 31 November 2019

\section{*Correspondence:}

Dr. S. Neeraja,

E-mail: sreeramneeraja2904@gmail.com

Copyright: (C) the author(s), publisher and licensee Medip Academy. This is an open-access article distributed under the terms of the Creative Commons Attribution Non-Commercial License, which permits unrestricted non-commercial use, distribution, and reproduction in any medium, provided the original work is properly cited.

\begin{abstract}
Background: Early alimentation after caesarean delivery probably has limited clinical significance in terms of improved energy and protein intake. Decreasing the post-operative ileus is possible with early feeding. Objective of this study was to study efficacy of early postoperative feeding versus conventional feeding for patients undergoing caesarean section.

Methods: Present study was hospital based comparative study carried out among 200 women who fulfilled the selection criteria. The cases were divided into 2 groups of 100 each by suitable random sampling technique. Group A included 100 cases who were given early feeding within 6 hours of caesarean delivery. Group B included 100 control who were given the feeding after 24 hours of caesarean delivery.

Results: The mean duration of postoperative hospital stay in Group A and Group B was 4.59 \pm 0.65 and $4.81 \pm 0.81$ days respectively $(\mathrm{p}<0.05)$. The mean time to return of bowel sounds in Group A and Group B was $2.79 \pm 1.36$ and $3.55 \pm 1.49$ hours respectively ( $\mathrm{p}<0.01) .2(2 \%)$ cases in group A had postoperative ileus symptoms, whereas $3(3 \%)$ cases in Group B had the same. Statistically significant difference ( $\mathrm{p}<0.05)$ was seen in terms of vomiting $1 \%$ versus $17 \%$, nausea $5 \%$ versus $16 \%$, abdominal distention $2 \%$ versus $7 \%$, diarrhea $4 \%$ versus $90 \%$ in the early feeding versus conventional feeding groups.

Conclusions: It can be concluded from present study that fast return to the normal diet is possible with early feeding among women undergoing cesarean section compared to the conventional feeding among women undergoing cesarean section.
\end{abstract}

Keywords: Caesarean section, Delivery, Diet, Feeding, Fetus, Incidence, Pregnancy

\section{INTRODUCTION}

Caesarean section is an operative procedure whereby the fetuses after the end of $28^{\text {th }}$ weeks are delivered through an incision on the abdominal and uterine walls. This excludes delivery through an abdominal incision where the fetus, lying free in the abdominal cavity following uterine rupture or in secondary abdominal pregnancy. The first operation performed on a patient is referred to as a primary cesarean section. When the operation is performed in subsequent pregnancies, it is called repeat cesarean section. Number of women undergoing cesarean section in increasing; last decade witnessed an increase from $10 \%$ to $2-3$ times more rate. ${ }^{1}$

The introduction of anesthesia, antibiotics and better understanding of fluids and electrolyte balance, free availability and advancement in blood transfusion have greatly reduced, the mortality and morbidity of the women who is undergoing caesarean section operation. 
Traditional postoperative care maintains, "Patients who have had uncomplicated surgery may be given clear liquids on the first postoperative day if bowel sounds are present, if abdominal examination reveals no distension, and if the patient is no longer nauseated from her anesthesia. After flatus is passed, the diet should be accelerated as tolerated to a regular diet". ${ }^{2}$

This approach has been based on the long-held assumption that initiating oral feeding immediately after surgery may result in nausea, vomiting, and abdominal distention. In recent years, traditional management of postoperative ileus has been challenged both after surgery of the gastrointestinal tract and after Caesarean delivery. Many studies have shown that early feeding is effective. ${ }^{3-}$

Patients undergoing caesarean are commonly young and healthy, and their bowel function generally returns rapidly following surgery. This early return of post caesarean bowel function has been attributed to the minimal bowel manipulation, relatively short duration of surgery, and low rate of peritonitis. ${ }^{6}$

Early alimentation after caesarean delivery probably has limited clinical significance in terms of improved energy and protein intake. Decreasing the post-operative ileus is possible with early feeding. ${ }^{7}$

Having normal bowel and decreased fever are important determinants of early discharge from the hospital. ${ }^{6,8}$

It is common that the normal amounts of gastric juices and the pancreatic juices are secreted even in the absence of oral intake. ${ }^{9}$

Patient body can absorb these high volumes of juices secreted after surgery even when they were not managed by putting nasogastric tube. ${ }^{6}$

Because these gastric and pancreatic juices get secreted, it can be safely assumed that oral feeding can be given early as they will tolerate it. It has been observed clinically that bowel function comes back even before the function signs can be detected clinically within 24 hours and small bowel starts functioning within 48 hours in majority of the cases after surgery. ${ }^{7}$

Present study was carried out to study the efficacy of early postoperative feeding versus conventional feeding for patients undergoing caesarean section.

\section{METHODS}

Present study was hospital based comparative study from October 2016 to April 2018.

The study was conducted in the Department of Obstetrics and Gynecology at SVS Medical College and Hospital, Mahbubnagar, Telangana, India.
Ethical approval for the study protocol and clearance were obtained from the Ethical Review Committee of SVS Medical College and Hospital, Mahbubnagar.

In this study, 200 women who fulfilled the selection criteria were included.

\section{Inclusion criteria}

- Women between 18-35 years of age

- Women who undergo cesarean delivery in SVS Medical College and Hospital

- With spinal and general anesthesia only.

\section{Exclusion criteria}

- Women with obstetric complications requiring admission to ICU/ ventilator support/ any other severe morbidity requiring ventilator support and unconscious patients were excluded in the study.

A total 200 pregnant women with term gestation undergoing caesarean section under spinal and general anesthesia were taken up for the study.

The cases were divided into 2 groups of 100 each by suitable random sampling technique.

- Group A (100 cases): Within 6 hours of caesarean delivery

- Group B (100 control): After 24 hours of caesarean delivery.

An informed consent was taken from the patients who met the inclusion criteria. These women underwent a thorough general and systemic examination like cardiovascular system, respiratory system, per abdomen and per vaginal examinations.

Spinal anesthesia was given and "10 mg hyperbaric bupivacaine ( $2 \mathrm{ml}$ of $0.5 \%$ bupivacaine $\mathrm{H}$ )" was given to all. Caesarean deliveries were carried out with standard protocol.

Post-operatively the women were randomly allocated into two groups as above. Women assigned in the early feeding group were motivated to take water in the first six hours post operatively. Then this group women were given liquid diet 6-8 hours post operatively. Then every 6-8 hours. After 12 hours, they were encouraged to take their regular diet.

Women in the other group were given sips of water only after first 24 hours of surgery. These women were given solid diet only after passing the flatus. Nausea was not treated, but metoclopramide $10 \mathrm{mg}$ was given in case of vomiting.

For women in the both groups, age, postoperative hospital stay (days), Time to return of bowel sounds 
(hours), postoperative morbidity was compared and measured.

\section{Statistical analysis}

Results are presented as mean $\pm \mathrm{SD}$ and range values and number and percentages. Z-test was used to compare the mean levels between two groups and chi-squire test for categorical data. A p-value of 0.05 or less was considered for statistical significance.

\section{RESULTS}

Table 1 shows maternal age distribution in two groups. in Group A, majority of women were in the age group of 21-24 years $(47 \%)$ and similar observation was recorded for women belonging to Group B also. This was followed by women in the age group of 26-30 years i.e. $35 \%$, and for women in the Group B, there were $39 \%$ in this age group. There were eight women in Group A and seven women in Group B in the age group of 31-35 years. there were ten women in Group A and seven women in Group $\mathrm{B}$ in the age group of less than 20 years. The difference between the two groups was not found to be statistically significant $(\mathrm{p}>0.05)$.

Table 1: Maternal age distribution in two groups.

\begin{tabular}{|lllll|}
\hline \multirow{2}{*}{ Age } & Group A & \multicolumn{3}{c|}{ Group B } \\
\hline$<20$ & No. & $\mathbf{\%}$ & No. & \% \\
\hline $21-25$ & 47 & 10 & 7 & 7 \\
\hline $26-30$ & 35 & 37 & 47 & 47 \\
\hline $31-35$ & 8 & 8 & 39 & 39 \\
\hline Total & $\mathbf{1 0 0}$ & $\mathbf{1 0 0}$ & $\mathbf{1 0 0}$ & $\mathbf{1 0 0}$ \\
\hline
\end{tabular}

Chi square -0.812 , $\mathrm{p}$ value $=0.847$.

Table 2: Comparison of variables in two groups.

\begin{tabular}{|llllll|}
\hline \multirow{2}{*}{ Variables } & Group & Mean & SD & T-value & p-value \\
\cline { 2 - 6 } & A & 25.40 & 3.72 & 0.369 & 0.712 \\
\cline { 2 - 6 } postoperative hospital stays (days) & B & 25.21 & 3.55 & & \\
\cline { 2 - 6 } & A & 4.5 & 0.65 & 2.11 & 0.036 \\
\hline \multirow{2}{*}{ Time to return of bowel sounds (hours) } & A & 4.8 & 0.81 & & $<0.001$ \\
\cline { 2 - 6 } & B & 2.79 & 1.36 & 3.72 & \\
\hline
\end{tabular}

Table 2 shows the age range of 200 women included in present study whose age range from 18-35 years In Group A, out of 100 women, 47 (47\%) were in age group of 21-25 years. In Group B, out of 100 women, 47 (47\%) were in the group of 21-25 years. The mean age in Group A was $25.4 \pm 3.72$ compared to Group B 25.21 \pm 3.55 . The $t$ -value 0.369 and $p=0.712(p>0.05)$, it is found that difference is statistically not significant. The mean duration of postoperative hospital stay in Group A and Group B was $4.59 \pm 0.65$ and $4.81 \pm 0.81$ days respectively. $\mathrm{P}<0.05$, it was found that statistical difference was significant. The mean time to return of bowel sounds in

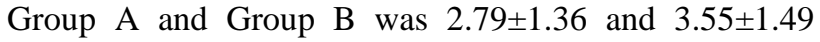
hours respectively. The t-value was 3.72 and $p<0.001$, it is found that difference is statistically highly significant.

Table 3: Indication for caesarean section in two groups.

\begin{tabular}{|c|c|c|c|c|}
\hline \multirow{2}{*}{ Indication for caesarean section } & \multicolumn{2}{|c|}{ Group A } & \multicolumn{2}{|c|}{ Group B } \\
\hline & No. & $\%$ & No. & $\%$ \\
\hline Fetal distress & 33 & 33 & 32 & 32 \\
\hline Not willing for VBAC & 37 & 37 & 28 & 28 \\
\hline CPD & 8 & 8 & 13 & 13 \\
\hline Previous LSCS & 8 & 8 & 8 & 8 \\
\hline Precocious pregnancy & 1 & 1 & 7 & 7 \\
\hline Prime with Breech & 6 & 6 & 3 & 3 \\
\hline Low BPP & 7 & 7 & 9 & 9 \\
\hline Total & 100 & 100 & 100 & 100 \\
\hline
\end{tabular}

Chi square -8.202 , p value -0.224 .

Table 3 shows the distribution of indication for caesarean section in two groups. In Group A, out of 100 women 37
(37\%) caesarean sections were done for not willing for VBAC. In Group B out of 100 women, 28 (28\%) 
caesarean sections were done for not willing for VBAC. There was no statistically significant relation observed between indication of caesarean section in between groups. $\mathrm{p}>0.05$.

Table 4 shows postoperative morbidity. 2 (2\%) cases in Group A had postoperative ileus symptoms, whereas 3 $(3 \%)$ cases in Group B had the same. The difference is found to be statistically not significant. There was $1(1 \%)$ cases of postoperative vomiting in Group A whereas 17 $(17 \%)$ cases had the same in Group B. The difference is statistically significant. $5(5 \%)$ cases in Group A developed postoperative nausea whereas $16(16 \%)$ cases in Group B had the same. The difference is statistically significant. $2(2 \%)$ patients in Group A developed abdominal distension postoperatively, whereas 7 (7\%) patients in Group B developed the same. The difference is statistically significant. $1(1 \%)$ cases in Group A had postoperative diarrhoea whereas $4(4 \%)$ cases had same in Group B. The difference is statistically not significant. $90(90 \%)$ cases in Group A had no GI complication whereas $51(51 \%)$ cases in Group B had no GI complications. The difference is statistically significant.

Table 4: Postoperative morbidity (GI complications).

\begin{tabular}{|lllll|}
\hline \multirow{2}{*}{ Indication for caesarean section } & Group A & & Group B & No. \\
\hline Ileus symptoms & No. & \% & 3 & 3 \\
\hline Vomiting & 2 & 2 & 17 & 17 \\
\hline Nausea & 1 & 1 & 16 & 16 \\
\hline Abdominal distension & 5 & 5 & 7 & 7 \\
\hline Diarrhea & 2 & 1 & 4 & 4 \\
\hline No complications & 1 & 90 & 51 & 51 \\
\hline Total & 90 & $\mathbf{1 0 0}$ & $\mathbf{1 0 0}$ & $\mathbf{1 0 0}$ \\
\hline
\end{tabular}

Chi square -37.9 , $\mathrm{p}$ value $-<0.001$.

\section{DISCUSSION}

Authors found that there was early and fast return in the function of the bowel in those who were given early feeding compared to women not given in the control group. They were able to pass the flatus early. It took on an average three hours compared to 3.62 hours for return of bowel function. This difference was found out to be statistically significant. This difference may be due to the fact that early stimulation of GI tract reduced the period of ileus which is common after surgery.

Ray SA et al, reported from their study in the patients underwent laparotomy, and given early oral fluids, found required less IV fluids and hydration was good. They stated that this leads to more patient satisfaction in terms of less invasion due to IV fluids even though IV canula is used to give parenteral antibiotics. ${ }^{10}$

Similar study also tried to assess the effect of giving early feeding in women undergoing cesarean section. Special diet was given. It contained glutamine and arginine. They are supposed to increase the cellular immunity, improve integrity of GI tract and also promote growth. The authors found that their special diet was very well accepted and tolerated by the women and there were no untoward effects reported. ${ }^{11}$

Information on ileus after surgery is wanting. Mac Millan et al, found that the incidence of ileus was $4.4 \%$ in their study population and incidence of severe ileus was $0.7 \% .^{12}$ Patolia DS et al, noted an incidence of $31.7 \%$ which was mild in nature who were given early feeding compared to $26.7 \%$ in women who were given conventional feeding. ${ }^{5}$ Gocmen $\mathrm{A}$ et al, observed that the $6 \%$ was the incidence of ileus in their study. They observed that the incidence of the ileus was slightly more in conventional feeding group compared to early feeding group..$^{5,12,13}$

Authors found that the incidence of nausea was $16 \%$ versus $5 \%$ in conventional group vs. early feeding group ( $\mathrm{p}<0.05$ ). Authors found that the incidence of vomiting was $17 \%$ versus $1 \%$ in conventional group versus early feeding group $(\mathrm{p}<0.05)$. Authors found that the incidence of diarrhea was $4 \%$ versus $1 \%$ in conventional group vs. early feeding group ( $\mathrm{p}<0.05)$. Diarrhea $1(1 \%)$ versus $04(4 \%)$ whose difference was statistically not significant. $2(2 \%)$ patients in Group A developed abdominal distension postoperatively, whereas 7 (7\%) patients in Group B developed the same. The difference is statistically significant. Authors found that the incidence of ileus was $3 \%$ versus $2 \%$ in conventional group vs. early feeding group $(\mathrm{p}>0.05)$.

Authors noted that women in early feeding group had lower incidence of ileus compared to the control group. Other authors observed that the incidence of ileus was $26-31 \%$. If the women received any opioid analgesics, then there is chance of emptying of the stomach very late 
moreover the oxytocin used to induce labor is a known emetogenic. ${ }^{14}$

Chantarasorn $\mathrm{V}$ et al, studied 200 patients out of which, 107 were in early feeding group and remaining in the conventional group. ${ }^{15}$ Both the groups were comparable demographically. They reported that the incidence of mild ileus was $19.6 \%$ compared to $31.1 \%$ in the conventional feeding group and the difference was statistically significant. Bowel movements also returned significantly early in the early feeding group compared to conventional feeding group. Requirement for IV fluids was also noted to significantly lesser and the duration of the stay in the hospital was also significantly lesser. ${ }^{15}$

Orji EO et al, observed in their study that they could hear bowel sounds in the early feeding group in on an average 18.9 hours in the early feeding group while it took on an average 36.21 hours for the conventional feeding group. ${ }^{16}$ Passage of flatus was also significantly lesser in the early feeding group compared to the conventional feeding group. Requirement of IV fluids was also lesser in the early feeding group compared to the conventional feeding group. Bowel movements also appeared significantly in lesser time in the early feeding group compared to the conventional feeding group. Duration of the hospital stay was also significantly in lesser time in the early feeding group compared to the conventional feeding group. ${ }^{16}$

Teoh WH et al, found that both the groups were comparable in terms of operative and demographic characteristics. ${ }^{17}$ Bowel movements also appeared significantly in lesser time in the early feeding group compared to the conventional feeding group. First drink time after surgery was significantly in lesser time in the early feeding group compared to the conventional feeding group. Solid food intake time after surgery was significantly in lesser time in the early feeding group compared to the conventional feeding group. Passage of flatus was also significantly lesser in the early feeding group compared to the conventional feeding group. Mothers in the early feeding group were more satisfied than the mothers in the conventional feeding group. ${ }^{17}$

\section{CONCLUSION}

In this era of post-operative surgical care, authors believe that traditions and principles untested in scientific based studies should be challenged. Postoperative patients managed without a nasogastric tube are able to absorb immediately these large volumes of secretion. Therefore, it seems reasonable that postoperative patients should be able to tolerate early, moderate oral intake. Early feeding has been advocated for both its nutritive value and positive, effects on the gastrointestinal tract, where such stimulation may decrease the duration of postoperative ileus. It can be concluded from present study that fast return to the normal diet is possible with early feeding among women undergoing cesarean section compared to the conventional feeding among women undergoing cesarean section.

Funding: No funding sources

Conflict of interest: None declared

Ethical approval: The study was approved by the Institutional Ethics Committee

\section{REFERENCES}

1. Suganya Devi S, Pilla SK, Vijayaraghavan J. A comparative study of early versus conventional delay in postoperative oral intake. Indian J Obstet Gynecol Res. 2015;2(4):276-82.

2. Adupa D, Wandabwa J. A randomized controlled trial of early initiation of oral feeding after caesarean delivery in Mulago hospital. East Afr Med J. 2003;80(7):345-50.

3. Soriano D, Dulitzki M, Keidar N, Barkai G, Mashiach S, Steidman DS. Early oral feeding after cesarean delivery. Obstet Gynecol. 1996;87:1006-8.

4. Shibata Y, Toyoda S. Patterns of intestinal motility recovery during the early stage following abdominal surgery: Clinical Manometric Study. World J Surg. 1997;21:806-10.

5. Patolia DS, Hiliard RLM Jr, Toy EC, Baker B. Early feeding after cesarean: randomized trial. Obstet Gynecol. 2001;98:113-6.

6. Strong TH Jr, Brown WL Jr, Brown WL, Curry CM. Experience with early post cesarean hospital dismissal. Am J Obstet Gynecol. 1993;169:116-9.

7. Gocmen A, Gocmen M, Saraoglu M. early postoperative feeding after caesarean delivery. J Int Med Res. 2002;30:506-11.

8. Brooten D, Roncoli M, Finkler S, Arnold L, Cohen A. A randomized trial of early hospital discharge and home follow-up of women having cesarean birth. Obstet Gynecol. 1994;84:832-8.

9. Bufo AJ, Feldman S, Daniels GA, Lieberman RC. Early postoperative feeding. Dis Colon Rectum. 1994;37:1260-5.

10. Ray SA, Rainsbury RM. Patient tolerance of the early introduction of oral fluids after laparotomy. Ann R Coll Surg Engl. 1993;75:157-60.

11. Weinstein L, Dyne PL, Duerbeck NB. The PROEF diet - A new postoperative regimen for oral early feeding. Am J Obstet Gynecol. 1993;168:128-31.

12. Nematihonar B, Salimi S, Noorian V, Samsami M. Early versus delayed (Traditional) postoperative oral feeding in patients undergoing colorectal anastomosis. Adv Biomed Res. 2018;7:30.

13. Gocmen A, Gocmen M, Saraoglu M. Early postoperative feeding after caesarean delivery. J Int Med Res. 2002;30:506-11.

14. Bar G, Sheiner E, Lezerovizt A, Lazer T, Hallak M. Early maternal feeding following caesarean delivery: A prospective randomized study. Acta Obstet Gynecol Scand. 2008;87(1):68-71.

15. Chantarasorn V, Tannirandom Y. A comparative study of early postoperative feeding versus 
conventional feeding for patients undergoing cesarean section; a randomized controlled trial. J Med Assoc Thai. 2006;89(Suppl 4):S11-6.

16. Orji EO, Olabode TO, Kuti O, Ogunniyi SO. A randomised controlled trial of early initiation of oral feeding after cesarean section. J Matern Fetal Neonatal Med. 2009;22(1):65-71.

17. Teoh WH, Shah MK, Mah CL. A randomised controlled trial on beneficial effects of early feeding
post-Caesarean delivery under regional anaesthesia. Singapore Med J. 2007;48(2):152-7.

Cite this article as: Neeraja S, Reddy N, Fathima N. A comparative study of early postoperative feeding versus conventional feeding for patients undergoing caesarean section. Int J Reprod Contracept Obstet Gynecol 2019;8:5002-7. 